\title{
A comparative assessment of the estimates of the saturated hydraulic conductivity of two anthropogenic soils and their impact on hydrological model simulations
}

\author{
Mouna FEKI ${ }^{1 *}$, GIOVANNI RAVAZZANI ${ }^{1}$, STEFANO BARONTINI ${ }^{2}$, \\ ALESSANDRO CEPPI ${ }^{1}$, MARCO MANCINI ${ }^{1}$ \\ ${ }^{1}$ Department of Civil and Environmental Engineering (D.I.C.A.), Politecnico di Milano, Milano, Italy \\ ${ }^{2}$ Dipartimento di Ingegneria Civile, Architettura, Territorio, Ambiente e di Matematica, \\ Università degli Studi di Brescia, Brescia (BS), Italy \\ "Corresponding author: mouna.feki@polimi.it
}

Citation: Feki M., Ravazzani G., Barontini S., Ceppi A., Mancini M. (2020): A comparative assessment of the estimates of the saturated hydraulic conductivity of two anthropogenic soils and their impact on hydrological model simulations. Soil \& Water Res., 15: 135-147.

\begin{abstract}
In this study, different methods were compared in order to determine the soil hydraulic conductivity at the saturation $\left(K_{\mathrm{s}}\right)$ of two heavily anthropized soils in northern Italy: an irrigated field and a landfill cover. In situ, laboratory measurements (falling head and evaporation method) and pedotransfer functions (ROSETTA and HYPRES) were used for the $K_{\mathrm{s}}$ estimation. In accordance with scientific literature, the results have shown that $K_{\mathrm{s}}$ is largely dependent on the type of technique used in taking the measurements. The ROSETTA and HYPRES pedotransfer functions show quite similar performances, while their easiness and convenient use make them potential alternative techniques for the $K_{\mathrm{s}}$ estimation in comparison with the in situ and laboratory measurements. The $K_{\mathrm{s}}$ estimate is sensitive to the selected method and this sensitivity affects the hydrological model simulations. Therefore, none of the tested methods can be considered as a benchmark, but the results found in this study confirm that the applied method for the determination of $K_{\mathrm{s}}$, may provide a first estimate of $K_{\mathrm{s}}$ to be subsequently optimised after the simulations.
\end{abstract}

Keywords: double ring infiltrometer; evaporation method; Guelph permeameter; hydraulic conductivity at soil saturation; laboratory experiments; pedotransfer functions

Modelling the soil hydrological processes greatly depends on the estimates of the soil hydraulic parameters, among which, the hydraulic conductivity at the soil saturation $\left(K_{\mathrm{s}}\right)$ plays a crucial role (De Pue et al. 2019). This parameter is required as the input for many ecological, hydrological, environmental and agricultural models, not only to characterise the plant-soil-atmosphere interactions, but also to characterise the compacted liners which are used for landfills as the final cover and which are subjected to restrictive regulations (Durner \& Lipsus 2005; Boscarello et al. 2015). Due to soil variability and complexity, getting a good estimate of $K_{\mathrm{s}}$ is not an easy task. In addition, the temporal and spatial variability of $K_{\mathrm{s}}$ strongly increases the difficulty to obtain its realistic estimate (Webb et al. 2000; Feki et al. 2018a). Generally, $K_{\mathrm{s}}$ is obtained through direct field and laboratory measurements or derived

\footnotetext{
Supported by the INNOMED Project "Innovative Options for Integrated Water Resources Management in the Mediterranean" (http://innomed.csic.es/), and the SIM Project "Smart Irrigation from Soil Moisture Forecast Using Satellite and Hydro-Meteorological Modelling" (http://www.sim.polimi.it/) funded by the Ministry for Education, University and Research of Italy within the EU Water Joint Programming Initiative.
} 
from inverse measurements (Dane \& Topp 2002). Laboratory methods play an important role in the determination of the soil hydraulic parameters as these methods are usually considered as the reference to estimate the saturated hydraulic conductivity (Fodor et al. 2011). In the laboratory, the $K_{\mathrm{s}}$ measurements are performed using the falling or constant head method on the undisturbed soil cores. Inverse modelling from the laboratory measurements (i.e., multistep outflow, evaporation method) is commonly used for determining the soil hydraulic parameters including $K_{\mathrm{s}}$ (Iovino \& Romano 2005) too. The hydraulic properties can be also estimated from the field measurements by inverse modelling. Laboratory tests are carried out in a controlled environment on undisturbed soil cores. Laboratory procedures are usually performed with fully saturated soil samples of known volume under controlled boundary conditions and flow geometry. Several field-measuring techniques exist such as an air entry permeameter, a double tube method, a ring infiltrometer, and well permeameter methods (Bouwer \& Jackson 1974). Field methods exhibit the advantages of a larger sampled soil volume and direct contact with the surrounding soil. Hence, some researchers consider field measurements to be representative of a realistic soil behaviour (Shouse \& Mohanty 1998; Basile et al. 2003). However, the field procedures pose major issues regarding the proper estimate of the correct field boundary conditions.

The implementation of the different methods to determine $K_{\mathrm{s}}$ even for the same study site usually produces different and sometimes incomparable results (Fallico et al. 2006). This outcome has been confirmed by many researchers, which have been interested in the evaluation of different $K_{\mathrm{s}}$ measuring techniques under different field conditions (Lee et al. 1985; Gupta et al. 1993; Mohanty et al. 1994; Huang et al. 2015). Lee et al. (1985) compared the results of $K_{\mathrm{s}}$ measurements from the Guelph permeameter, air entry permeameter and falling head method in Southern Ontario. Mohanty et al. (1994) compared four in situ $K_{\mathrm{s}}$ measuring methods (Guelph permeameter, velocity permeameter, disk permeameter and double tube method) together with the $K_{\mathrm{s}}$ determination in the laboratory on undisturbed soil samples for the glacial-till soil of Nicollet. Huang et al. (2015) compared the $K_{\mathrm{s}}$ measured by the Guelph permeameter with an air permeameter for three types of reclamation soils near Fort McMurray in Alberta Canada. Gupta et al. (1993) conducted a similar study with four in situ methods (double-ring infiltrometer, rainfall simulator, Guelph permeameter, and Guelph infiltrometer) in Ottawa, Canada.

All these investigated methods, although aimed at determining the same parameter $\left(K_{\mathrm{s}}\right)$, yielded different results. The tested field measurements often provided smaller values of $K_{\mathrm{s}}$ than the laboratory techniques. Further reasons for which the $K_{\mathrm{s}}$ data is different is based on the used method of measurement. Many authors affirmed that such a result might be due to the air trapped during the wetting, hence the soil is not fully saturated and correctly shows a smaller conductivity (Fodor et al. 2011; Jačka et al. 2014; Rezaei et al. 2016). Barontini et al. (2005, 2009), based on field and laboratory campaigns to estimate the hydraulic properties of mountain soils, observed that the $K_{\mathrm{s}}$ estimates obtained with a single ring infiltrometer may be higher or, on average, comparable with those obtained by means of a laboratory falling head permeameter.

The field and laboratory measurements which are usually considered as the most accurate determination methods may also exhibit a certain level of error, depending on the study site conditions, sample collection and disturbance, and instrument installation (Jačka et al. 2014 and Reynolds \& Elrick 1986). Hence, the applicability of a specific technique should be tested for each study site.

The selection of the most adequate method for the $K_{\mathrm{s}}$ determination should consider several criteria: cost, labour, accuracy and speed (Ibrahim \& Aliyu 2016). Another important aspect that influences the $K_{\mathrm{s}}$ estimation, is the observation scale of the applied method. Moreover, despite the ability of the laboratory and field measurements to better determine the soil related parameters and particularly the saturated hydraulic conductivity, these methods remain costly and time consuming especially for large study areas (Wösten et al. 2001).

Therefore, there was a need to develop less timeconsuming methods (Bouma \& Van Lanen 1987). In recent years, many pedotransfer functions (PTFs) have been proposed to put some soil hydraulic parameters (here: $K_{\mathrm{s}}$ ) into relationships with other easily obtainable soil properties. These functions started to be widely used, but their applicability within a given study area requires validation (Durner \& Lipsius 2005). In their tests of several PTFs in the Po Valley, Ungaro and Calzolari (2001) showed satisfactory performances of some tested PTFs for modelling purposes.

In this study, several techniques to measure or estimate of $K_{\mathrm{s}}$ (Guelph permeameter, double ring 
https://doi.org/10.17221/33/2019-SWR

infiltrometer, laboratory falling head method, laboratory evaporation method, and some common pedotransfer functions) were tested. These results were compared and their effectiveness for being used to properly represent the soil water dynamics was assessed.

Aimed at contributing to understanding the effect of the different methods to estimate the hydraulic conductivity at soil saturation and its effect on soil modelling results using the estimates for practical purposes, this study has different purposes, it $(i)$ compares in situ and laboratory methods to estimate $K_{\mathrm{s}}$, (ii) tests different fitting equations for the laboratory evaporation method used for the $K_{\mathrm{s}}$ estimate, and ( $\left.i i i\right)$ evaluates the relevance of the selected pedotransfer functions (PTFs) for the $K_{\mathrm{s}}$ estimation. The resulting $K_{\mathrm{s}}$ values were used to assess the effect of the uncertainty, induced from the implemented method to estimate $K_{\mathrm{s}}$, on 1D water flow simulations.

\section{MATERIAL AND METHODS}

Study sites. Measurements of $K_{\mathrm{s}}$ were carried out during 2015 at two sites located in Northern Italy (Figure 1A). We selected these two study sites due to the particular importance of the soil characterisation for such land uses. The first site (A, $45^{\circ} 13^{\prime} 31.70^{\prime \prime} \mathrm{N}$, $\left.9^{\circ} 36^{\prime} 26.82^{\prime \prime} \mathrm{E}\right)$, is an agricultural field located in Secugnago (Po river floodplain, province of Lodi). This field belongs to the irrigation consortium of Muzza Bassa Lodigiana (MBL). The measurements in this study site were carried out within the framework of the SEGUICI project (Smart technologies for water resources management for civil consumption and irrigation, Ravazzani et al. 2017), which are aimed at evaluating the use of soil water content forecast for irrigation scheduling. This field is annually cropped with maize, which is a typical cultivation in this area. The meteorological data, together with soil water content, were monitored. The field was equipped with a meteorological and an eddy covariance station. The rainfall was measured by a rain gauge (AGR100 by Campbell Scientific) for the quantification of the precipitation amounts. The soil water content measurements were carried out using TDR probes (CS616 by Campbell Scientific) that were installed at three different soil depths $(10,35 \mathrm{~cm}$ and $60 \mathrm{~cm})$.

The second study site (B, 44 $\left.28^{\prime} 1.44^{\prime \prime} \mathrm{N}, 8^{\circ} 51^{\prime} 17.80^{\prime \prime} \mathrm{E}\right)$ is a landfill, established in 1968 on Monte Scarpino (province of Genoa). It covers the bottom valley of the Cassinelle creek with a surface area of $0.52 \mathrm{~km}^{2}$. This landfill is one of the largest in Europe and has been operational since the early sixties for collecting the municipal solid waste (MSW) of Genoa and of its province at a rate of about 1000 tonnes/day (Mancini et al. 2018). The landfill's vertical profile displays several deposits of waste subdivided by layers of compacted soil down to a depth of about

(A)

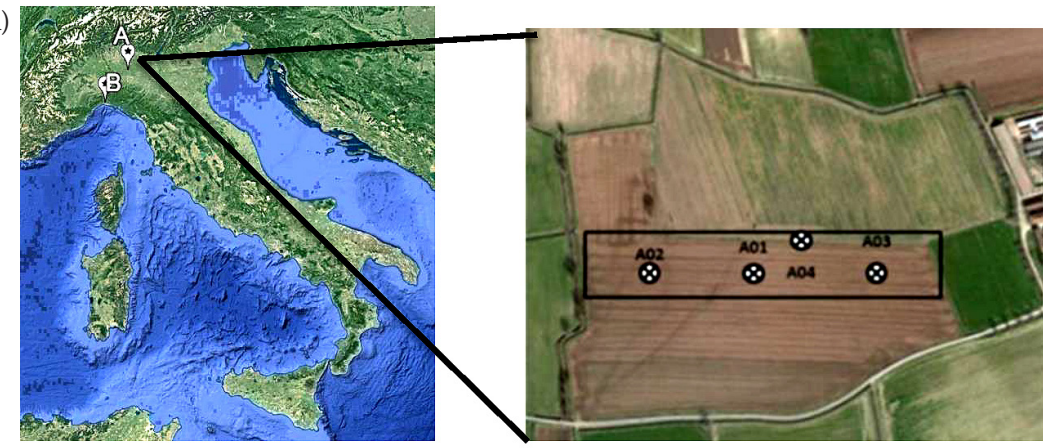

(B)

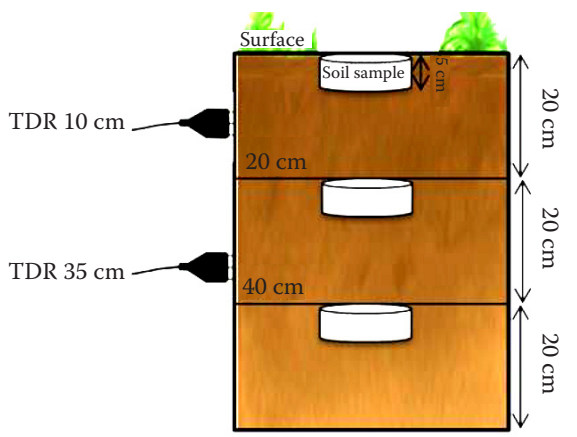

Figure 1. The study sites and sampling location of site A (A) and the schematic presentation of the soil samples and the TDR probes locations (site A) (B) 
70 meters. The site has been monitored for several years showing great fluctuations in the leachate level especially under high rainfall rate conditions. A compacted soil layer was designed as the final cover in order to reduce the amount of water that infiltrates through the waste. For this site, the soil properties determination was performed on the compacted soil liner. Both study sites were used to test the $K_{\mathrm{s}}$ estimates using different fitting equations (Mualem 1976) and the predictive model of relative hydraulic conductivity with Brooks and Corey (BC) (1964) and van Genuchten (VG) (1980) soil water retention relationships) for the evaporation method data and to evaluate the relevance of the selected pedotransfer functions for the $K_{\mathrm{s}}$ estimate, within the selected study area. In addition, the Guelph permeameter measurements were carried out. Only for the site (B), double ring infiltrometer (DRI) tests were performed together with the Guelph permeameter (GP) in order to compare the two in situ $K_{\mathrm{s}}$ measuring methods (GP vs DRI). More details about the implemented techniques are reported in the Electronic Supplementary Material.

Soil sampling. The undisturbed soil samples were collected using a steel cylinder with an $8 \mathrm{~cm}$ inner diameter and $5 \mathrm{~cm}$ in length. In the Secugnago site, the soil samples were collected at different points referred to as: A01, A02, A03 and A04, (Figure 1A, B) at different soil depths (from 0 to $20 \mathrm{~cm}$; from 20 to $40 \mathrm{~cm}$ and from 40 to $60 \mathrm{~cm}$ ). The three sampling depths were referred as: 0,20 and $40 \mathrm{~cm}$ respectively. Part of the field where A01, A02, A03 were collected was used for the cultivation of maize. Another part of the field was left uncultivated for more than 8 years from which the A04 samples were taken. These samples were analysed with both a falling head permeameter and an evaporation method. For the landfill of Scarpino, (B-0) refers to the samples that were taken from the compacted liner on the soil surface.

For both of the study sites, the undisturbed soil samples were collected for the laboratory measurements of the $K_{\mathrm{s}}$ and bulk density. The disturbed soil samples were used to measure the other soil properties, e.g., the organic matter content and the soil texture, required as input for the PTFs. Three to five replicates of the soil samples for each sampling point were collected. The distance separating the replicates was, at a maximum, $20 \mathrm{~cm}$ in order to avoid too many effects of the soil lateral spatial variability. In addition, the samples were collected on the same day during which the $K_{\mathrm{s}}$ field measurements were carried out in order to avoid the temporal variability of the soil properties.

In Table 1, the particle size distribution, the bulk density (BD), the organic matter content (SOM) and the USDA (United States Department of Agriculture) taxonomy are reported for the investigated samples. The dry bulk density was calculated from the soil

Table 1. The soil properties of the collected samples

\begin{tabular}{|c|c|c|c|c|c|c|}
\hline \multirow{2}{*}{ Sampling location } & Sand & Clay & Silt & \multirow{2}{*}{$\begin{array}{c}\mathrm{BD} \\
\left(\mathrm{g} / \mathrm{cm}^{3}\right)\end{array}$} & \multirow{2}{*}{$\begin{array}{c}\text { SOM } \\
\text { (\% by weight) }\end{array}$} & \multirow{2}{*}{$\begin{array}{l}\text { Textural class } \\
\text { (USDA taxonomy) }\end{array}$} \\
\hline & \multicolumn{3}{|c|}{ (\% by weight) } & & & \\
\hline \multicolumn{7}{|l|}{ Secugnago site A } \\
\hline A01 & 72 & 5 & 23 & 1.47 & 3.76 & sandy loam \\
\hline A02 & 76 & 4.75 & 19.25 & 1.62 & 3.67 & loamy sand \\
\hline A03 & 71.5 & 5.25 & 23.55 & 1.49 & 3.91 & sandy loam \\
\hline A04 & 76.66 & 4.5 & 18.83 & 1.55 & 6 & loamy sand \\
\hline \multirow{3}{*}{$20 \mathrm{~cm}$} & 71.46 & 7.5 & 21.04 & 1.64 & 3.05 & sandy loam \\
\hline & 68.44 & 9 & 22.56 & 1.69 & 3.21 & sandy loam \\
\hline & 60.83 & 6 & 33.17 & 1.69 & 3.48 & sandy loam \\
\hline A04 & 73.63 & 4.5 & 21.87 & 1.7 & 3.29 & sandy loam \\
\hline A01 & 73.19 & 6 & 20.81 & 1.69 & 2.96 & sandy loam \\
\hline A02 & 72.48 & 5 & 22.51 & 1.62 & 3.19 & sandy loam \\
\hline A03 & 73.58 & 4.75 & 21.66 & 1.71 & 2.97 & sandy loam \\
\hline A04 & 73.5 & 5.5 & 20.91 & 1.76 & 3 & sandy loam \\
\hline \multicolumn{7}{|l|}{ Scarpino site B } \\
\hline B-0 & 0 & 8 & 92 & 1.9 & 0 & silt \\
\hline
\end{tabular}

BD - Bulk density; SOM - soil organic matter content 
https://doi.org/10.17221/33/2019-SWR

dry weight, by oven-drying at $105^{\circ} \mathrm{C}$ for $24 \mathrm{~h}$, and the known volume of the sampling ring. The particle size distribution for each soil was determined by wet sieving and the hydrometer method. The sand, silt and clay contents together with the soil texture were identified according to the USDA system of soil classification. The sites at A and B were classified as sandy loam and silty, respectively, according to the USDA. The SOM was determined for each sample using the loss-on-ignition (LOI) method. This method consists of measuring the weight loss before and after exposing the soil sample to high temperature, which is correlated to the organic matter content. The LOI method is considered to be inexpensive and gives accurate estimates of the organic matter content (Cambardella et al. 2001).

$K_{s}$ measuring and estimation techniques. Different methods were implemented for the measurement of $K_{s}$. In the laboratory measurements, the $K_{\mathrm{s}}$ determination was performed on the undisturbed soil samples with the falling head and constant head permeameter. The hydraulic conductivity at the soil saturation was determined using a KSAT-UMS instrument (KSAT 2012), which is a laboratory apparatus that is designed to measure $K_{\mathrm{s}}$. The second laboratory measurements were carried out following the evaporation method on the undisturbed soil samples using a HYPROP-UMS Hydraulic Property Analyzer (HYPROP 2010).

The HYPROP-UMS is an instrument which uses the Wind/Schindler evaporation method in the tensiometer range. The evaporation method, firstly presented by Wind (1966) and simplified, as implemented in the HYPROP, by Schindler (1980), is one of the widely used methods to determine the soil hydraulic properties. Although many in situ methods for measuring $K_{\mathrm{s}}$ exist, for the interest of this study, only two of them were used, namely the Guelph permeameter and the double ring infiltrometer. For the field measurements, at each location, the measurements were repeated 5 times with a minimum average distance of around $1 \mathrm{~cm}$ in order to avoid the effect of the spatial variability of the soil properties.

In addition, for this study, ROSETTA (Shaap et.al. 1996) and HYPRES (Hydraulic Properties of European Soils, Wösten et al. 1999) pedotransfer functions were implemented (Table 2). ROSETTA is a software which implements five hierarchical pedotransfer functions for the estimation of the saturated hydraulic conductivity and soil water retention curve parameters according to the van Genuchten (1980)-Mualem (1976) framework. For this study, only the first three PTFs of ROSETTA were implemented ( $R 1, R 2$ and $R 3$ ). $R 1$ requires the soil textural classes according to the (USDA) classification as the input based on a simple lookup table. The other PTFs implemented within ROSETTA, among which are R2 and R3, are based on neural network analyses to estimate the soil parameters combined with the bootstrap method that allows the program to estimate the uncertainty of the predicted parameters (Shaap 1996). The HYPRES PTF was also tested in this study (Wösten et al. 1999). This PTF is derived from the European soil database through regression equations linking the physical soil properties to the soil hydraulic ones. These pedotransfer functions, in principle, allow the estimating of all of the soil hydraulic parameters, while, for this study, our focus was on assessing the estimation accuracy of the saturated hydraulic conductivity.

Model simulations. The soil water content simulations were carried out using different values of

Table 2. The estimate of the vertical saturated hydraulic conductivity $\left(K_{\mathrm{s}}\right)$ with ROSETTA and HYPRES pedotransfer functions (PTFs) and the related input data and HYPRES PTFs

\begin{tabular}{|c|c|c|}
\hline PTF-author & & $K_{\mathrm{s}}$ mathematical expression \\
\hline $\begin{array}{l}\text { HYPRES, } \\
\text { Wösten et al. (1999) }\end{array}$ & & $\begin{array}{c}\ln \left(K_{\mathrm{s}}\right)=7.755+(0.0352 \times \mathrm{S})+(0.93 \times \text { topsoil })-\left(0.967 \times \mathrm{BD}^{2}\right)-\left(0.000484 \times \mathrm{C}^{2}\right)+ \\
-\left(0.000322 \times \mathrm{S}^{2}\right)+\left(0.001 \times \mathrm{S}^{-1}\right)-\left(0.0748 \times \mathrm{OM}^{-1}\right)-(0.643 \times \ln (\mathrm{s}))+-(0.01398 \times \\
\mathrm{BD} \times \mathrm{OM})+(0.02986 \times \text { topsoil } \times \mathrm{C})-(0.03305 \times \text { topsoil } \times \mathrm{S})\end{array}$ \\
\hline \multicolumn{3}{|l|}{ PTFs input data } \\
\hline \multirow{3}{*}{$\begin{array}{l}\text { ROSETTA, } \\
\text { Schaap and Bouten } \\
(1996)\end{array}$} & R1 & soil textural class \\
\hline & R2 & neural network requiring $\% \mathrm{Cl}, \% \mathrm{Si}$ and $\% \mathrm{Sa}$ \\
\hline & R3 & neural network requiring $\% \mathrm{Cl}, \% \mathrm{Si}, \% \mathrm{Sa}$ and $\mathrm{BD}$ \\
\hline
\end{tabular}

$\mathrm{S}$ - percent of the silt; $\mathrm{C}$ - percent of the clay; BD - bulk density; OM - organic matter content; top soil (in this study, used for the surface soil samples) or subsoil (in this study, used for the samples taken at $20 \mathrm{~cm}$ and $40 \mathrm{~cm}$ ) are qualitative variables having the value of 1 or 0 , respectively 
$K_{\mathrm{s}}$ resulting from the tested methods for the determination of this parameter for the Secugnago site only. The simulations were carried out using data related to the surface sample of location A01, since it was the closest to the meteorological and soil water content sensors among the other sampling points. The simulation period lasted from 01/05/2015 until $17 / 09 / 2015$. The soil water retention curve and conductivity curve parameters, presented in Table 3 , are determined according to the van Genuchten equation from the evaporation method experiments.

The soil water content simulations were carried out using the FEST-WB, an acronym for "Flash flood Event-based Spatially-distributed rainfall-runoff Transformations-Water Balance" has been developed at Politecnico di Milano since 1990 (Ceppi et al. 2014). Several options for the calculation of the infiltration exist within the FEST-WB. For this study, a $1 \mathrm{D}$ water flow in the upper part of the soil layers was simulated according to the numerical scheme proposed by Ross (2003). The computational domain is discretised by a mesh of a squared cell, $1 \mathrm{~m}$ per side. The discretisation of time and space is considered to be a classic system. The soil depth considered for these simulations was $50 \mathrm{~cm}$. The soil profile is divided into $\mathrm{n}$ horizons with a thickness of $5 \mathrm{~cm}$ each, while the simulations were carried out with hourly time steps. The installed TDR that provided the soil moisture measurements are installed at 10 $\mathrm{cm}$ and $35 \mathrm{~cm}$, so both the simulated and observed soil moisture values at these depths were available. The potential evapotranspiration (ETP) was computed based on the Hargreaves-Samani equation (Hargreaves \& Samani 1985). The ETP was adjusted to the crop evapotranspiration and the crop coefficient $K_{\mathrm{c}}$ was taken from the FAO 56 report (Allen et al. 1998). The initial conditions were set in terms of the water content. For this study, we set the $\theta$ values equal to $\theta_{s}$, since our simulation period started after a heavy rainfall event, thus, the soil was saturated. The upper boundary condition (BC) was set to the atmospheric $\mathrm{BC}$ while free drainage was assumed at the bottom of the soil profile.

Table 3. The soil hydraulic parameters from the evaporation method fitted to van Genuchten of A01 - the surface sample used as inputs for the FEST-WB

\begin{tabular}{lccccc}
\hline Location & $\begin{array}{c}\alpha^{\prime \prime} \\
(1 / \mathrm{cm})\end{array}$ & $n$ & $\begin{array}{c}\theta_{\mathrm{s}} \\
\left(\mathrm{cm}^{3} / \mathrm{cm}^{3}\right)\end{array}$ & $l$ & $m$ \\
\hline A01 & 0.006 & 1.164 & 0.48 & 0.5 & 0.141 \\
\hline
\end{tabular}

A local sensitivity analysis was carried out for all the soil hydraulic parameters by the info in Feki et al. (2018b). The results showed that the model was more sensitive to the saturated hydraulic conductivity and saturated water content compatibly for all the implemented infiltration models in the FEST-WB. For this reason, we decided to focus our simulations only on the effect of the method used to determine the $K_{\mathrm{s}}$ parameter on the model output and particularly on the soil moisture.

The performance of the different estimates of $K_{\mathrm{s}}$ on the soil water content simulations was assessed using the root mean square error (RMSE) and the Nash-Sutcliffe efficiency (NSE).

The RMSE is given by the following formula:

$\mathrm{RMSE}=\left[\frac{1}{n} \sum_{K=1}^{n}\left(y_{k}-\hat{y}_{k}\right)^{2}\right]^{1 / 2}$

where:

$n$ - the number of observations

$y$ - the field measured soil water content

$\hat{y}$ - the estimated soil water content

The NSE proposed by Nash and Sutcliffe (1970) is calculated as:

$\mathrm{NSE}=1-\frac{\sum_{i=1}^{n}\left(O_{i}-P_{i}\right)^{2}}{\sum_{i=1}^{n}\left(O_{i}-\bar{O}\right)^{2}}$

where:

$O_{i}$ - the field measured soil water content

$P_{i}$ - the simulated soil water content

$\bar{O}$ - the mean of the observed soil water content

The NSE coefficient varies between 1 (perfect fit) and $-\infty$.

\section{RESULTS AND DISCUSSIONS}

Results of the tested methods. The Guelph permeameter measurements were carried out at three locations in the first study site, and at one location in the second field. Double ring infiltrometer tests were performed at the Scarpino site. Table 4 shows the comparison between the field measurements and laboratory measurements of $K_{\mathrm{s}}$ at the different sampling locations. It is worth noting that the Guelph permeameter measurements were carried out at a soil depth of $16 \mathrm{~cm}$, due to the auger depth. For all the study areas, the soil was vertically homogeneous, thus, similar $K_{\mathrm{s}}$ values were found at the soil surface and at a depth of $20 \mathrm{~cm}$ (as presented in Table 5 for 
https://doi.org/10.17221/33/2019-SWR

Table 4. The field $v s$. laboratory soil hydraulic conductivity at the saturation $\left(K_{\mathrm{s}}\right)$ measurements

\begin{tabular}{lcrcc}
\hline \multirow{2}{*}{ Location } & & Guelph & $K_{\mathrm{s}}-$ UMS & Double ring \\
\cline { 3 - 5 } & & \multicolumn{3}{c}{$(\mathrm{cm} /$ day $)$} \\
\hline \multirow{3}{*}{ Site A } & A01 & 0.27 & 1.40 & - \\
& A02 & 2.08 & 30.75 & - \\
\multirow{2}{*}{ Site B } & A04 & 39.92 & 509.17 & - \\
\hline
\end{tabular}

the Secugnago site). The measurements were carried out at the beginning of the cropping cycle. According to these considerations, the Guelph permeameter results were compared to the laboratory measurements carried out on the surface samples.

Two or three replicates of each measuring technique at each location were performed. Moreover, two double ring infiltrometer tests were performed within the Scarpino landfill. This soil is an artificial compacted soil, where samples for the KSAT-UMS tests were collected from the upper first centimetres of the soil profile and the different depths gave the same results for $K_{\mathrm{s}}$. The same was true for the other tested soil characteristics (such as the bulk density and the particle size distribution). The different implemented techniques gave almost the same result as the KSAT-UMS test for the surface samples $(0 \mathrm{~cm})$ (Table 4$)$. Both field methods yielded an underestimation of the $K_{\mathrm{s}}$ value when compared to the laboratory test. Considered as a less destructive method of the soil structure, the double ring infiltrometer measurement yielded a bit higher value $(0.13 \mathrm{~cm} /$ day $)$, than the Guelph permeameter $(0.07 \mathrm{~cm} /$ day $)$. The $K_{\mathrm{s}}$ values of this compacted liner were considered out of the range of validity for both field techniques; however, the values found through these measurements were comparable to the laboratory ones.

The Guelph permeameter measurements underestimated the $K_{\mathrm{s}}$ value as compared with the laboratory falling head method. For the majority of the sampling points, the difference even exceeded one order of magnitude. The tests carried out within these sites confirmed the results found by Dorsey et al. 1990, Mohanty et al. 1994, Reynolds 2008, and Jačka et al. 2014 about the underestimation of the $K_{\mathrm{s}}$ value when the Guelph permeameter measurements is used as compared to the other measurement methods. It may be assumed that this behaviour is due to the borehole preparation as mentioned above in the introduction.

Some comparisons of the different measuring techniques of $K_{\mathrm{s}}$ showed that the laboratory measurements gave higher values than the field measurements (Kanwar et al. 1989). However, this result may not

Table 5. The values of the soil hydraulic conductivity at saturation $\left(K_{\mathrm{s}}, \mathrm{cm} /\right.$ day $)$ by the method, location and depth, and descriptive statistics of these values: average (mean, $\mathrm{cm} /$ day), standard deviation (SD, $\mathrm{cm} /$ day) and coefficient of variation $(\mathrm{CV})$

\begin{tabular}{|c|c|c|c|c|c|c|c|c|c|c|c|c|}
\hline \multirow{2}{*}{$\begin{array}{l}\text { Study } \\
\text { site }\end{array}$} & \multirow[b]{2}{*}{ Sample } & \multirow{2}{*}{$\begin{array}{c}\text { Depth } \\
(\mathrm{cm})\end{array}$} & \multicolumn{3}{|c|}{ Laboratory methods } & \multicolumn{4}{|c|}{ PTFs } & \multirow[b]{2}{*}{ Mean } & \multirow[b]{2}{*}{ SD } & \multirow[b]{2}{*}{$\mathrm{CV}(\%)$} \\
\hline & & & EVAP-VG & EVAP-BC & $\begin{array}{l}\text { falling } \\
\text { head }\end{array}$ & $\mathrm{R} 1$ & $\mathrm{R} 2$ & R3 & HYPRES & & & \\
\hline \multirow{12}{*}{ A } & A01 & \multirow{4}{*}{0} & 0.95 & 0.16 & 1.4 & 38.25 & 17.33 & $\underline{42.75}$ & 90 & 27.26 & 30.45 & 111.69 \\
\hline & A02 & & 30.42 & 0.48 & 30.75 & $\underline{105.12}$ & 24.83 & 29.58 & 66.33 & 41.07 & 31.63 & 77.01 \\
\hline & A03 & & $\underline{164.17}$ & 20.67 & 5.79 & 38.25 & 64.08 & 70.83 & 83.25 & 63.86 & 48.37 & 75.74 \\
\hline & A04 & & 4.88 & 0.17 & $\underline{509.17}$ & 105.12 & 81.08 & 82.08 & 39.33 & 117.41 & 164.18 & 139.84 \\
\hline & A01-20 & \multirow{4}{*}{20} & $\underline{98.4}$ & 3.41 & 1.65 & 38.25 & 55 & 36.84 & 3.67 & 33.89 & 32.77 & 96.69 \\
\hline & A02-20 & & 19.87 & 17.08 & 28 & 38.25 & $\underline{46.17}$ & 22.5 & 32.5 & 29.2 & 9.72 & 33.28 \\
\hline & A03-20 & & 15.6 & 5.25 & 5.1 & 38.25 & $\underline{56.33}$ & 22.17 & 32.5 & 25.03 & 17.3 & 69.14 \\
\hline & A04-20 & & 1.57 & 0.77 & 33.75 & 38.25 & $\underline{71.42}$ & 38.92 & 52.17 & 33.83 & 23.69 & 70.01 \\
\hline & A01-40 & \multirow{4}{*}{40} & 1.73 & 0.06 & 1.63 & 38.25 & $\underline{63.83}$ & 36.42 & 33.83 & 25.11 & 22.68 & 90.35 \\
\hline & A02-40 & & 4.54 & 0.38 & 1.07 & 38.25 & 66.67 & $\underline{84.17}$ & 68 & 37.58 & 33.28 & 88.54 \\
\hline & A03-40 & & 3.29 & 0.32 & 1.98 & 38.25 & $\underline{70.08}$ & 69.42 & 54 & 33.91 & 29.46 & 86.90 \\
\hline & A04-40 & & 60.23 & 5.26 & 1.02 & 38.25 & $\underline{66.58}$ & 30.42 & 27.67 & 42.86 & 41.19 & 96.09 \\
\hline B & B-0 & 0 & 0.09 & 0.06 & 0.33 & $\underline{43.74}$ & 17.73 & 2.13 & 4.2 & 9.75 & 15.04 & 154.21 \\
\hline
\end{tabular}

PTFs - pedotransfer functions; the underlined values in the table refer to the highest estimated $K_{s}$ value for each sample 
always be valid for an artificial homogeneous soil at the landfill study site, since the laboratory falling head and in situ tests gave quite similar results, hence, the validity of some tests greatly depends on the tested soil conditions.

The soil cores used for the laboratory experiments were the UMS-sampling rings with a volume of $250 \mathrm{~cm}^{3}$. All the tested samples except sample A04, do not present sight-recognisable macropores since the samples were collected at the beginning of the cropping cycle. Sample A04 which presented some macropores (Figure 2) was taken from an uncultivated part of the soil where a greater number of earthworms and grass roots were observed.

Table 5 presents the results of $K_{\mathrm{s}}$ determined with the laboratory techniques and PTFs. The results show that the determination of $K_{\mathrm{s}}$ is largely affected by the type of the selected method for the determination of this parameter. The effect of the $K_{\mathrm{s}}$ determination method for each sampling location and at different soil depths was assessed using the arithmetic mean (Mean), the standard deviation (SD) and the coefficient of variation (CV).

For the agricultural field (site A), the highest values of the SD and CV for the determination of $K_{s}$ were recorded for the surface soil sample at location A04 since the difference between the tested methods reached two orders of magnitude with a CV of $139.84 \%$. These values were smaller for the other locations where the macro-porosity was apparently absent.

For the samples located in the cultivated part of the field, the CV ranged between $33.28 \%$ and $111.69 \%$. All the measurements were performed within the upper $40 \mathrm{~cm}$ of the soil. The soil at this depth is considered as greatly subjected to lateral surface variability. Coherent with the literature for the case of heterogeneous soils (Fodor et al. 2011), the spatial variability of $K_{\mathrm{s}}$ can yield to a coefficient of variation even higher than $100 \%$ for small sites with measurements carried out with the same method.

For the landfill site (B), the difference between the values of $K_{\mathrm{s}}$ determined by the different methods reached two orders of magnitude difference and a high CV was recorded with a value of $154.21 \%$.

The HYPROP tests were carried out for all the collected samples from both study sites. Even if the reliability of the $K_{\mathrm{s}}$ values obtained from this method has been sometimes questioned, some researchers, who used this method, take the value of $K_{\mathrm{s}}$ obtained from the HYPROP measurement in their hydrological simulations together with other estimated soil water retention curve parameters into account (SCHWEN et al. 2014).

The evaporation method experiments were carried out to determine all the soil hydraulic properties; however, in this study, only the $K_{\mathrm{s}}$ values are discussed.

Although the validity should be tested before being applied (Iovino \& Romano 2005), only a few studies exist to assess the effect of the selection of the hydraulic conductivity equations for the estimation of $K_{\mathrm{s}}$, therefore, the collected data from this experiment were used in order to be fitted for the two selected equations.

It is worth noting that the used software, HYPROPFIT, does not require initial estimates for the fitting process. For this study, Brooks and Corey (1964) and van Genuchten unimodal (1980) SWRC were implemented. However, the difference for some samples was not so pronounced (e.g., A01-0 cm, A04-20, and B-0). The results reported in Table 5 show the dependency of this parameter estimation on the selected soil water retention curve parametric equation. This outcome confirms the result found by Ventrella et al. (2005) where the $K_{\mathrm{s}}$ estimate definitely depends on the selected parametric equation. Compared to the calculated arithmetic mean, this method tends to underestimate the value of $K_{\mathrm{s}}$ for both BC and VG.

In our case, in contrast with the result found by Ventrella et al. (2005) for a tested fine textured soil, the VG-unimodal gave the closest results for $K_{\mathrm{s}}$ to the falling head measurements for an agricultural field characterised by a coarse soil texture.

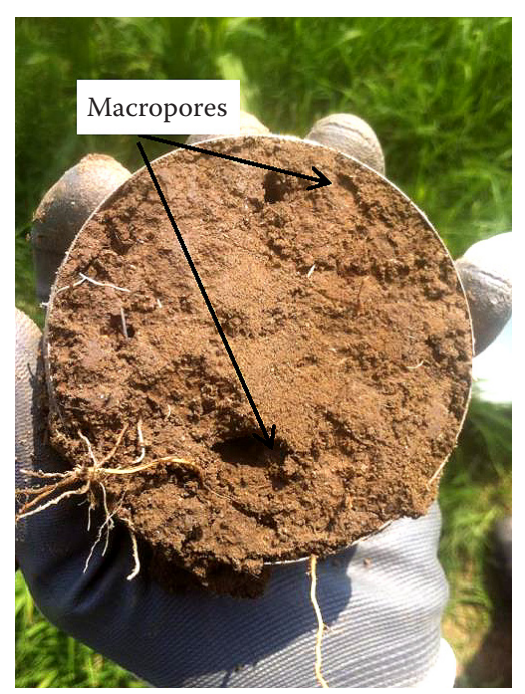

Figure 2. The soil sample-A04 sampling location 
https://doi.org/10.17221/33/2019-SWR

For the compacted liner of the landfill (B-0), the difference between the two laboratory methods was not so pronounced. The selection of the parametric equation for evaporation method for this sample did not show a significant impact on the results of $K_{\mathrm{s}}$.

The collected basic soil properties, required as inputs for the tested pedotransfer functions (PTFs), ROSETTA (Schaap \& Bouten 1996) and HYPRES (Wösten et al. 1999), are reported in Table 1. The tested soil textures of both study sites were included within both databases from which these pedotransfer functions were developed (sandy loam and silty soils). The evaluation of these PTFs, as presented in Table 5, has proven that the tested PTFs for this study site provided an overestimation of $K_{\mathrm{s}}$ when compared to the laboratory measurements for all the sampling locations except A04.

Even if $\mathrm{R} 2$ and $\mathrm{R} 3$ require more inputs, for the agricultural field, R1 gave quite similar estimates of $K_{\mathrm{s}}$ except for the A04 sampling point with respect to R2 and R3. Better estimates of $K_{\mathrm{s}}$ were found for $20 \mathrm{~cm}$ and $40 \mathrm{~cm}$ depths where the soil was quite homogeneous and less disturbed.
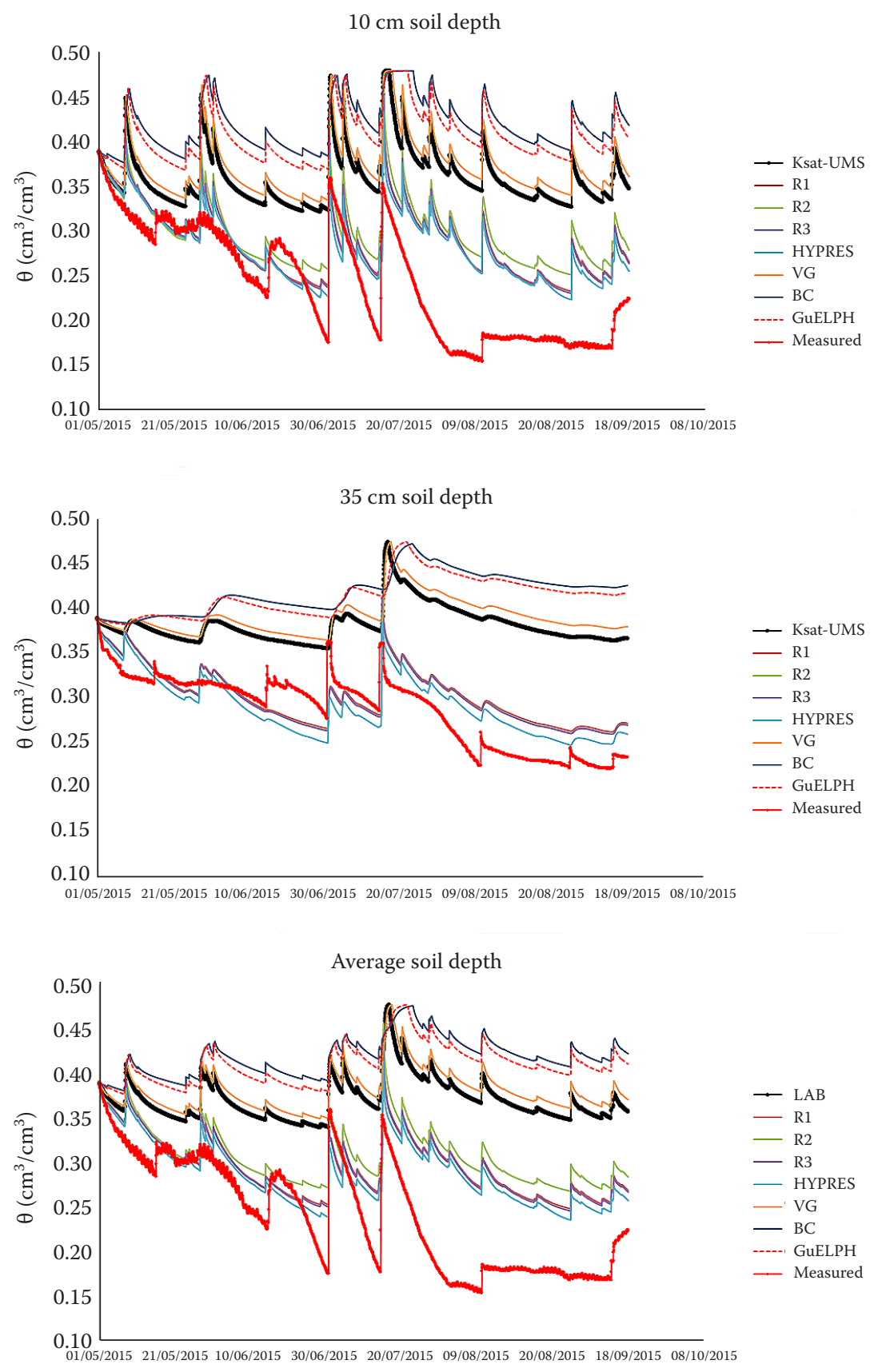

Date
Figure 3. The soil water content simulation using the different measured and estimated hydraulic conductivity at the saturation values for the A01 sampling location at the Secugnago site, $2015(10 \mathrm{~cm}, 35 \mathrm{~cm}$ and average soil depths) 
For the compacted liner, closer estimates of $K_{\mathrm{s}}$ to laboratory methods as estimated by the PTFs were observed between R1, R2 and R3. This soil was compacted with a high bulk density value $\left(1.9 \mathrm{~g} / \mathrm{cm}^{3}\right)$. The higher bulk density usually leads to a smaller saturated hydraulic conductivity (Cameira et al. 2003). HYPRES and R3 also require the bulk density as an input, which explains the improvement of the $K_{\mathrm{s}}$ estimates when compared to R2 and R1. Despite this improvement, the estimated $K_{\mathrm{s}}$ values remain over-estimated as compared to the measurements of the other tested techniques.

Results of soil water content simulations. The simulations were carried out without calibration and the difference among the series of the simulated water content is due only to the implemented $K_{\mathrm{s}}$ values. The simulations were carried out for the sampling point A01. It has been confirmed through a study conducted within the same agricultural field that the soil hydraulic parameters, among which the saturated hydraulic conductivity are subjected to temporal variability, make a perfect fit impossible between the simulations and the measurements (Feki et al. 2018a).

In order to evaluate the effect of the selected method for the determination of $K_{\mathrm{s}}$, several model runs were carried out with different estimated and measured $K_{\mathrm{s}}$ values. The other soil hydraulic parameters were defined according to the van Genuchten-Mualem model.

The graphical comparison of the simulations of the soil water content based on the different $K_{\mathrm{s}}$ determination techniques (Figure 3 ) shows the sensitivity of the model to this parameter. In order to better quantify the effect of the $K_{\mathrm{s}}$ measuring technique on the performances of the soil water content simulations, the RMSE and NSE coefficients were calculated at different soil depths $(10 \mathrm{~cm}, 35 \mathrm{~cm}$ and at an avage depth which refers to the weighted average of the soil moisture between $0-40 \mathrm{~cm}$ soil depth)) as presented in Table 6. According to Figure 3 and Table 6 , the field and laboratory determined $K_{\mathrm{s}}$ values, which provided the smallest $K_{\mathrm{s}}$ estimates, gave the highest soil water content values with the smallest accuracy during the simulation period at the different soil depths, while better simulations were achieved when the $K_{\mathrm{s}}$ estimated values using PTFs were implemented.

Most of the values of the NSE obtained from the analysis of the soil water content simulation results were negative, which was mostly observed for the field and laboratory $K_{\mathrm{s}}$ based simulations, due to the model overestimation as compared to the field measurements.

On the contrary, the best simulation performances were achieved from the implementation of the $K_{s}$ values estimated through the PTFs, the RMSE ranging between $\left(0.8 \mathrm{~cm}^{3} / \mathrm{cm}^{3}\right.$ for $\left.\mathrm{R} 2\right)$ and $\left(0.06 \mathrm{~cm}^{3} / \mathrm{cm}^{3}\right.$ for HYPRES) for the average soil depth. The calculated NSE coefficient associated to these simulations confirmed the same findings, varying between ( -0.32 for $\mathrm{R} 2)$ and (0.32 for HYPRES) for the average soil depth. Among the tested PTFs, HYPRES allowed one to reach the best simulation results. This outcome confirms that the direct measurements do not always lead to the best results when implemented for the hydrological simulations. The same results were found by Baroni et al. (2010) where the estimated soil hydraulic parameters through the PTFs yielded better results than the field and laboratory measured parameters. The result found in this study confirms that the PTFs could be implemented as an easy and less time-consuming alternative to the direct measurements for the modelling purposes. Taking these results into consideration, the validity of these PTFs could be confirmed from this study for the field within which measurements were performed.

Table 6. The root mean square error (RMSE, $\mathrm{cm}^{3} / \mathrm{cm}^{3}$ ) and the Nash-Sutcliffe efficiency coefficient (NSE) between the simulated and measured soil water content for the A01 sampling location $(10 \mathrm{~cm}, 35 \mathrm{~cm}$ and average soil depth)

\begin{tabular}{lccrrrrrrrr}
\hline $\begin{array}{l}\text { Soil depth } \\
(\mathrm{cm})\end{array}$ & Method & $\begin{array}{c}\text { LAB } \\
\text { (KSAT-UMS) }\end{array}$ & R1 & R2 & R3 & HYPRES & HYPROP-VG & HYPROP-BC & Guelph \\
\hline \multirow{2}{*}{10} & RMSE & 0.17 & 0.09 & 0.1 & 0.09 & 0.09 & 0.19 & 0.24 & 0.23 \\
& NSE & -3.58 & -0.09 & -0.42 & -0.06 & 0.06 & -4.38 & -8.4 & -7.24 \\
35 & RMSE & 0.14 & 0.04 & 0.06 & 0.04 & 0.03 & 0.15 & 0.19 & 0.18 \\
& NSE & -5.77 & 0.32 & -0.16 & 0.36 & 0.47 & -7.11 & -11.76 & -10.95 \\
\multirow{2}{*}{ Average } & RMSE & 0.16 & 0.07 & 0.08 & 0.06 & 0.06 & 0.17 & 0.21 & 0.20 \\
& NSE & -4.6 & 0.12 & -0.32 & 0.16 & 0.32 & -5.66 & -10.15 & -9.06 \\
\hline
\end{tabular}


https://doi.org/10.17221/33/2019-SWR

\section{CONCLUSIONS}

Two heavily anthropized soils (an agricultural field and a landfill cover) were investigated to comparatively assess the soil hydraulic conductivity at saturation with different field and laboratory methods and pedotransfer functions. The method used to determine the hydraulic conductivity at the soil saturation may be regarded to as a major source of uncertainty to assess the soil hydrologic behaviour under field conditions.

According to the results of this study, the field methods (GP and DRI) provided a smaller $K_{s}$ than laboratory techniques, which is consistent with the result of the research conducted by Bagarello and Provenzano (1996). Particularly, the Guelph permeameter provided the smallest values of $K_{\mathrm{s}}$ probably due to the borehole preparation and air entrapment according to the literature. The falling head laboratory method, considered as less time and labour consuming, seems to be an accurate alternative for the field measurements for the determination of $K_{\mathrm{s}}$ for the tested compacted soil liner for landfills. Regarding the $K_{\mathrm{s}}$ estimates obtained from the evaporation method, it is worth noting that the value of this parameter depends on the selected parametric equation during the fitting process of the experimental results. For this reason, the equation that provides a more accurate result should be accurately selected for the determination of $K_{\mathrm{s}}$ for a given study site. The tested pedotransfer functions for such field scale studies gave an overestimation of $K_{\mathrm{s}}$ as compared to the laboratory falling head measurements. The ROSETTA textural classes based on PTF R1 was also able to give a $K_{\mathrm{s}}$ with one order of magnitude difference as compared to the laboratory measurements in many cases. The use of such a PTF would not probably be applicable for a field with a fully developed crop or after any agronomic practice, since it does not consider any other factors that affect the $K_{\mathrm{s}}$ such as bulk density or organic matter. R2, R3 and HYPRES that still require more input parameters did not result in the improvement of the $K_{\mathrm{s}}$ estimation as compared to $\mathrm{R} 1$ tested for the agricultural field. On the contrary, for the compacted liner, R3 and HYPRES resulted in a better estimate of $K_{\mathrm{s}}$ when compared to the other tested PTFs. This result confirms that the validity and the accuracy of the PTFs greatly depend on the tested soil conditions.

In this study, none of the tested methods was considered as a benchmark. Each of the tested techniques exhibits some advantages and limitations. The use of the $K_{\mathrm{s}}$ values determined by the different methods as the input for the hydrological simulation proved that the field or laboratory measurements do not always yield the best simulation results. Considering the time, labour and cost requirement, when implementing the laboratory and field measurement of the soil hydraulic parameters, the outcome of this study showed that the use of PTFs may also be considered as a good alternative to the direct measuring techniques.

\section{REFERENCES}

Allen R.G., Pereira L.S., Raes D., Smith M. (1998): Crop Evapotranspiration: Guidelines for Computing Crop Water Requirements. Irrigation and Drainage Paper No. 56, Rome, FAO.

Bagarello V., Provenzano G. (1996): Factors affecting field and laboratory measurement of saturated hydraulic conductivity. Transactions of the American Society of Agricultural Engineers, 39: 153-159.

Baroni G., Facchi A., Gandolfi C., Ortuani B., Horeschi D., van Dam J.C. (2010): Uncertainty in the determination of soil hydraulic parameters and its influence on the performance of two hydrological models of different complexity. Hydrology and Earth System Sciences, 14: 251-270.

Barontini S., Clerici A., Ranzi R., Bacchi B. (2005): Saturated hydraulic conductivity and water retention relationships for Alpine mountain. In: de Jong C., Collins D., Ranzi R. (eds.): Climate and Hydrology of Mountain Areas. Hoboken, John Wiley: 101-121.

Barontini S., Clerici A., Ranzi R., Bacchi B. (2009): A methodology to map the surface soil saturated hydraulic conductivity in mesoscale Alpine basins. In: Marks D. (ed.): Hydrology in Mountain Regions: Observations, Processes and Dynamics. IAHS Publication No. 326, Wallingford, IAHS: $112-118$.

Basile A., Mele G., Terribile F. (2003): Soil hydraulic behavior of a selected benchmark soil involved in the landslide of Sarno 1998. Geoderma, 117: 331-346.

Boscarello L., Ravazzani G., Cislaghi A., Mancini M. (2015): Regionalization of flow-duration curves through catchment classification with streamflow signatures and physiographic-climate indices. Journal of Hydrologic Engineering, 21: 05015027.

Bouma J., van Lanen H.A.J. (1987): Transfer functions and threshold values: from soil characteristics to land qualities. In: Beek K.J., Burrough P.A., McCormack D.E. (eds.): Proc. ISSS/SSSA Workshop on Quantified Land 
https://doi.org/10.17221/33/2019-SWR

Evaluation Procedures. Publication No. 6, Enschede, International Institute for Aerospace Survey and Earth Science: $106-111$.

Bouwer H., Jackson R.D. (1974): Determining soil properties. In: van Schilfgaarde J. (ed.): Drainage for Agriculture. ASA Agronomy Monograph No. 17, Madison, ASA: 611-672.

Brooks R.H., Corey A.T. (1964): Hydraulic Properties of Porous Media. Hydrologic Paper No. 3, Fort Collins, Colorado State University.

Cambardella C.A., Gajda A.M., Doran J.W., Wienhold B.J., Kettler T.A. (2001): Estimation of particulate and total organic matter by weight loss-on-ignition. In: Lal R. et al. (eds.): Assessment Methods for Soil Carbon. Boca Raton, Lewis Publications: 349-359.

Cameira M.R., Fernando R.M., Pereira L.S. ( 2003): Soil macropore dynamics affected by tillage and irrigation for a silty loam alluvial soil in southern Portugal. Soil \& Tillage Research, 70: 131-140.

Ceppi A., Ravazzani G., Corbari C., Salerno R., Meucci S., Mancini M. (2014): Real-time drought forecasting system for irrigation management. Journal of Hydrology and Earth System sciences, 18: 3353-3366.

Dane J.H., Topp C. (2002): Methods of Soil Analysis. $1^{\text {st }}$ Ed., Madison, Soil Science Society of America.

De Pue J., Rezei M., Van Mervenne M., Cornelis Win M. (2019): The relevance of measuring saturated hydraulic conductivity: Sensitivity analysis and functional evaluation. Journal of Hydrology, 576: 628-638.

Dorsey J.D., Ward A.D., Fausey N.R., Bair E.S. (1990): A comparison of four field methods for measuring saturated hydraulic conductivity. Transactions of the American Society of Agricultural Engineers, 33: 1925-1931.

Durner W., Lipsius K. (2005): Determining soil hydraulic properties. In: Anderson M.G. (ed.): Encyclopedia of Hydrological Sciences, Chapter 75, Chichester, John Wiley \& Sons: $1121-1143$

Fallico C., Migliari E., Troisi S. (2006): Comparison of three measurement methods of saturated hydraulic conductivity. Hydrology and Earth System Sciences Discussions, 3: 987-1019.

Feki M., Ravazzani G., Ceppi A., Mancini M. (2018a): Influence of soil hydraulic variability on soil moisture simulations and irrigation scheduling in a maize field. Agricultural Water Management, 202: 183-194.

Feki M., Ravazzani G., Ceppi A., Milleo G., Mancini M. (2018b): Impact of infiltration process modelling on soil water content simulations for irrigation management. Water, 10: 850.

Fodor N., Sándor R., Orfanus T., Lichner L., Rajkai K. (2011): Evaluation method dependency of measured saturated hydraulic conductivity. Geoderma, 165: 60-68.
Gupta R.K., Rudra R.P., Dickinson W.T., Patni N.K., Wall G.J. (1993): Comparison of hydraulic conductivity measured by various field methods. Transactions of the American Society of Agricultural Engineers, 36: 51-55.

Hargreaves G.H., Samani Z.A. (1985): Reference crop evapotranspiration from temperature. Transactions of the American Society of Agricultural Engineers, 1: 96-99.

Huang M., Rodger H., Barbour S.L. (2015): An evaluation of air permeability measurements to characterize the saturated hydraulic conductivity of soil reclamation covers. Canadian Journal of Soil Science, 95: 15-26.

HYPROP (2010): HYPROP-UMS - Operation Manual. Munich, UMS GmbH.

Ibrahim M.M., Aliyu J. (2016): Comparison of methods for saturated hydraulic conductivity determination: Field, laboratory and empirical measurements (A Pre-view). British Journal of Applied Science \& Technology, 15: 1-8. Iovino M., Romano N. (2005): Inverse modeling of evaporation and multistep outflow experiments for determining soil hydraulic properties: a comparison. Rivista di Ingegneria Agraria, 2: 51-62.

Jačka L., Pavlásek J., Kuráž V., Pech P. (2014): A comparison of three measuring methods for estimating the saturated hydraulic conductivity in the shallow subsurface layer of mountain podzols. Geoderma, 219-220: 82-88.

Kanwar R.S., Rizvi H.A., Ahmed M., Horton R., Marlev S.J. (1989): Measurement of field-saturated hydraulic conductivity by using Guelph and velocity permeameters. Transactions of the American Society of Agricultural Engineers, 32: 1885-1890.

KSAT (2012): KSAT-UMS Operation Manual. Munich, UMS GmbH.

Lee D.M., Reynolds W.D., Elrick D.E., Clothier B.E. (1985): A comparison of three field methods for measuring saturated hydraulic conductivity. Canadian Journal of Soil Science, 65: 563-573.

Mancini M., Ceppi A., Curti D., Ravazzani G., Feki M., Cerri L., Galletti L., Meucci S., Bianchi M., Senesi C., Cinquetti P. (2018): Real time monitoring of hydrological variables for operative landfill stability and percolation flux control. Environmental Engineering and Management Journal, 17: 2337-2348.

Mohanty B.P., Ankeny M.D., Horton R., Kanwar R.S. (1994): Spatial analysis of hydraulic conductivity measured using disc infiltrometers, Water Resources Research, 30: 2489-2498.

Mualem Y. (1976): A new model for predicting the hydraulic conductivity of unsaturated porous media. Water Resources Research, 12: 513-522.

Nash J.E., Sutcliffe J.V. (1970): River flow forecasting through conceptual models part I - A discussion of principles. Journal of Hydrology, 10: 282-290. 
https://doi.org/10.17221/33/2019-SWR

Ravazzani G., Corbari C., Ceppi A., Feki M., Mancini M., Ferrari F., Gianfreda R., Colombo R., Ginocchi M., Meucci S., De Vecchi D., Dell'Acqua F., Ober G. (2017): From (cyber)space to ground: new technologies for smart farming. Hydrology Research, 48: 656-672.

Reynolds W.D. (2008): Saturated hydraulic properties: Well permeameter. Chapter 76. In: Soil Sampling and Methods of Analysis, $2^{\text {nd }}$ Ed., Boca Raton, CRC Press.

Reynolds W.D., Elrick D.E. (1986): A method for simultaneous in-situ measurements in the vadose zone of field saturated hydraulic conductivity, sorptivity, and the conductivity pressure head relationship. Ground Water Monitoring Review, 6: 84-89.

Rezaei M., Seuntjens P., Shahidi R., Joris I., Boënne W., Al-Barri B., Cornelis W. (2016): The relevance of in-situ and laboratory characterization of sandy soil hydraulic properties for soil water simulations. Journal of Hydrology, 534: 251-265.

Ross P.J. (2003): Modeling soil water and solute transport - fast simplified numerical solutions. Agronomy Journal, 95: $1352-1361$.

Schaap M.G., Bouten W. (1996): Modeling water retention curves of sandy soils using Neural Networks. Water Resources Research, 32: 3033-3040.

Schindler U. (1980): Ein Schnellverfahren zur Messung der Wasserleitfähigkeit im teilgesättigten Boden an Stechzylinderproben. Archives of Agronomy and Soil Science, 44: $1-7$.

Schwen A., Zimmermann M., Bodner G. (2014): Vertical variations of soil hydraulic properties within two soil profiles and its relevance for soil water simulations. Journal of Hydrology, 156: 169-181.
Shouse P.J., Mohanty B.P. (1998): Scaling of near-saturated hydraulic conductivity measured using disc infiltrometers, Water Resources Research Journal., 34: 1195-1205.

Ungaro F., Calzolari C. (2001): Using existing soil databases for estimating water-retention properties for soils of the Pianura Padano-Veneta region of North Italy. Geoderma, 99: 99-121.

van Genuchten M. (1980): A closed-form equation for predicting the hydraulic conductivity of unsaturated soils. Soil Science Society of America Journal, 44: 892-898.

Ventrella D., Losavio N., Vonella A.V., Leij F.J. (2005): Estimating hydraulic conductivity of a fine-textured soil using tension infiltrometry. Geoderma, 124: 267-277.

Webb T.H., Claydon J.J., Harris S.R. (2000): Quantifying variability of soil physical properties within soil series to address modern land-use issues on the Canterbury Plains, New Zealand. Australian Journal of Soil Research, 38: $1115-1129$.

Wind G.P. (1966): Capillary conductivity data estimated by a simple method. In: Proc. UNESCO/IASH Symp. Water in the Unsaturated Zone, Wageningen: 181-191.

Wösten J.H.M., Lilly A., Nemes A., Le Bas C. (1999): Development and use of a database of hydraulic properties of European soils. Geoderma, 90: 169-185.

Wösten J.H.M., Pachepsky Y.A., Rawls W.J. (2001): Pedotransfer functions: bridging the gap between available basic soil data and missing soil hydraulic characteristics. Journal of Hydrology, 251: 123-150.

Received: April 3, 2019 Accepted: October 14, 2019 Published online: December 6, 2019 